International Journal of Trend in Scientific Research and Development (IJTSRD)

Volume: 3 | Issue: 2 | Jan-Feb 2019 Available Online: www.ijtsrd.com e-ISSN: 2456 - 6470

\title{
Green Supply Chain Management: A Primer
}

\author{
Matthew N. O. Sadiku1', Adedamola A. Omotoso², Sarhan M. Musa1 \\ 1Professor, ${ }^{2}$ Student \\ 1,2Roy G. Perry College of Engineering, Prairie View A\&M University, Prairie View
}

\begin{abstract}
Green supply chain management (GSCM) is about incorporating the environmental idea in every stage of a supply chain. It has emerged as a set of managerial practices that integrate environmental issues into supply chain management. It includes product design, material selection, manufacturing process, and delivery of the final product to consumers. The aim of GSCM is to minimize or eliminate wastage including hazardous chemical, emissions, energy and solid waste along supply chain. This paper provides a primer on GSCM.
\end{abstract}

Keywords: supply chain management, green supply chain management, supply chain environmental management, sustainable supply chain management

\section{INTRODUCTION}

Environment pollution and depletion of resources have been a major concern over the last decades. As the environmental awareness is increasing, companies are facing pressure from different stakeholders including government and customers to reduce or eliminate their harmful effect on the environment. Today, most organizations are going green in their business in view of environmental sustainability. They have realized that integration of environmental management practices across all departments of organizations is necessary in order to maintain competitive advantage.

Traditional supply chains move from the raw material state to the end product. There is a growing need to integrate environmental considerations into supply chain management.

Environmental sustainability practices in the supply chain are often referred to as green supply chain management (GSCM). Sustainable or green supply chain management aims at integrating environmental thinking into supply chain management. This includes product design, material selection, manufacturing process, and delivery of the final product to consumers. The key factors driving for green initiatives include [1]: (1) government compliance, (2) competitive global markets, (3) customer expectations, (4) financial return on investment (ROI), (5) reverse logistics, (6) supply chain efficiency, and (7) corporate social responsibility.

\section{SUPPLY CHAIN MANAGEMENT}

The supply chain consists of all parties involved in fulfilling a customer request, including the suppliers, transporters, warehouses, retailers, and customers. Supply chain management (SCM) stands for the chain connecting each element of the manufacturing and supply process from raw materials through to the final customers. It is basically based on interactions of manufacturing, logistics, materials, distribution, and transportation functions within an enterprise.

The concept of SCM was developed in 1970s by focusing on outsourcing, assembling, and delivery of products to customers. The past decade has seen a high demand and development of supply chain management. The supply chain is the movement of materials as they move from their source to the end customer. Supply chains play a crucial role even in service dominant economies. They are embodied in all sectors such as in automobiles, retail, and IT.

Traditional supply chain management is only concerned with the delivery of products from buyer to customer. It does not focus on society and the environment. Making green the supply chain is the process of shifting focus from cost or quality issues to also include the environmental and social dimensions of sustainability. The environmental concerns led the companies to incorporate mechanisms regarding disposal, recovery, recycling, and reuse of material. As the supply chain becomes more global, sustainability of supply chain deserves a broader attention.

\section{CONCEPT OF GREEN SUPPLY CHAIN MANAGEMENT}

The concept of green supply chain originates from the notion of green purchasing proposed by Webb in 1994. Green supply chain management (GSCM) or sustainable supply chain managemen, is a comprehensive philosophy developed recently to support companies and governments to improve their environmental sustainability. GSCM is different from SCM in terms of goal, management structure, business model, business process, and consumption pattern. The evolution of green supply chain management can be attributed to the increasing awareness among governments, organizations, and customers on increasing pollution, carbon emissions, and deteriorating environmental conditions.

GSCM is based on two concepts: the supply chain management and the environmental management. Thus the goal of GSCM is to integrate environmental thinking into the traditional supply chain management (SCM). GSCM consists of green purchasing, product design, green logistics, green manufacturing, green packaging, green marketing, and green recycling $[2,3]$. These are known as GSCM determinants and are illustrated in Figure 1.

- Green Purchasing: This is a process through which environmentally preferable goods and services are selected. It tries to minimize the environmental impacts of selected products and services. 
$>$ Green Design: It is the process of designing environmentally compatible products and services.

$>$ Reverse Logistics: This involves greening the supply chain backwards, i.e, starting from the downstream supply chain towards the upstream.

$>$ Green Manufacturing: This is the renewal of production processes and the establishment of environmentallyfriendly operations within the manufacturing sector.

> Green Packaging: Packaging design is important for attaining a company's environmental objectives.

$>$ Green Marketing: This involves the promotion or advertising of products. It includes environmentfriendly packaging and environment-friendly distribution.

$>$ The green philosophy of environmental protection is used as guide throughout the marketing process.

> Green Recycling: This involves recycling products and packages. It aims at having waste products recycled through manufacturing and remanufacture.

GSCM is important in many economic sectors such as construction industry, manufacturing, paper industry, automotive industry, maritime industry, power industry, chemical/petroleum industry, and electronics industry.

\section{BENEFITS AND CHALLENGES}

Green supply chain management has several advantages. It helps a company gain a competitive advantage and attract new customers. It improves financial performance and reduces risk by avoiding hazardous material. Other benefits for a company include greater efficiency of assets, improve brand image, less waste elimination, greater innovation, reduction of production costs, mitigation of risks and innovations, reuse of raw materials, improved productivity, increased profitability, and improved overall company performance [4]. Some of these benefits are illustrated in Figure 2. Leading multinational corporations such as WalMart and P \& G have achieved tremendous results in the practice of supply chain management.

There are still challenges in the implementation of GSCM. These include significant costs, the complexity of coordination, lack of green training, and lack of communication within the whole supply chain. Market demand is a major external barrier. Lack of top management commitment is a crucial barrier to the successful implementation of GSCM. The implementation of reverse logistics practices in organizations is challenging for both the economy and the ecology [5].

\section{CONCLUSION}

Green supply chain management (GSCM) refers to the concept of integrating sustainable environmental processes into the traditional supply chain. It is integrating environmental thinking into supply chain management (SCM). It is integrated into the entire process including planning, procurement, production, consumption, and reverse logistics. It is an evolving, fast-moving, and multidisciplinary field. Its knowledge domain is developing fast. More information about GSCM can be found in books in [6-9].

\section{REFERENCES}

[1] A. S. Dube and R. R. Gawande," Green supply chain management - A literature review," International Journal of Computer Applications, 2011.
[2] N. Gajendrum, "Green supply chain management Benefits challenges and other related concepts," International Journal of Applied Science Engineering \& Management, vol. 3, no. 8, 2017.

[3] M. A. Wibowo, N. U. Handayani, and A. Mustikasarn, "Factors for implementing green supply chain management in the construction industry," Journal of Industrial Engineering and Management, vol. 11, no. 4, 2018, pp. 651-679.

[4] A. Ali et al., "Green supply chain management - food for thought?," International Journal of Logistics Research and Applications, vol. 20, no. 1, 2017, pp. 22-38.

[5] V. Balon, A. K. Sharma, and M. K. Barua, "Assessment of barriers in green supply chain management using ISM: A case study of the automobile industry in India,. "Global Business Review, vol. 17, no. 1, 2016, pp. 116135.

[6] J. Morana, Sustainable Supply Chain Management. John Wiley \& Sons, 2013.

[7] J. Sarkis and Y. Dou, Green Supply Chain Management: A Concise Introduction. Routledge, 2017.

[8] J.Sarkis, Green Supply Chain Management. New York: ASME, 2014.

[9] C. Achillas et al., Green Supply Chain Management. Taylor \& Francis, 2018.

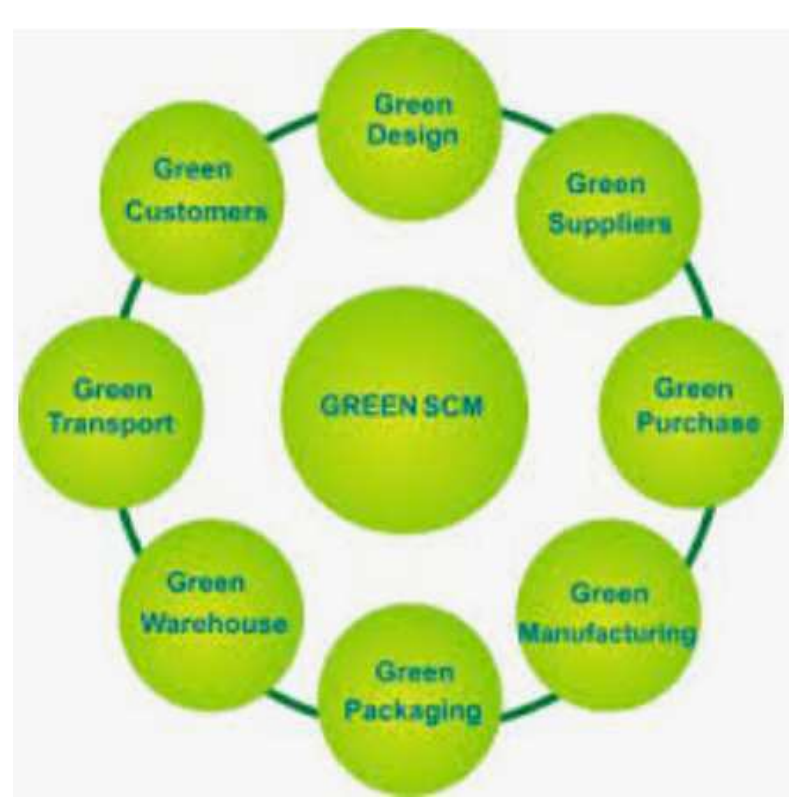

Figure 1 Different components of GSCM.

Source: http://www.greenhome.com/blog/green-supplychain-management

\section{Benefits Of Green SCM}

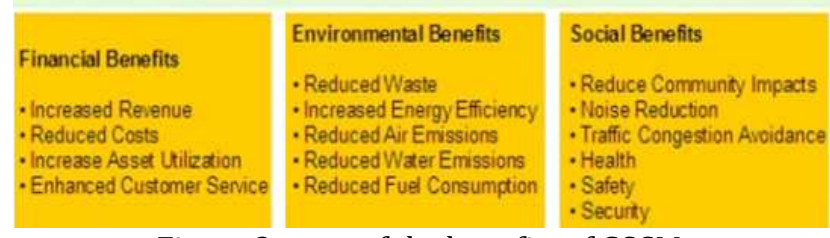

Figure 2 some of the benefits of GSCM.

Source: https://www.slideshare.net/sandyskadam/greensupply-chain-management-8714198 